\title{
Exploring prediction model and survival strategies for pulmonary hemorrhage in premature infants: a single-center, retrospective study
}

\author{
Jing $\mathrm{Li}^{1}$, Hejie $\mathrm{Xia}^{1}$, Lin $\mathrm{Ye}^{2}$, Xiaoxia $\mathrm{Li}^{1}$, Zhiqun Zhang ${ }^{1}$ \\ ${ }^{1}$ Department of Neonatology, Affiliated Hangzhou First People's Hospital, Zhejiang University School of Medicine, Hangzhou, China; ${ }^{2}$ Department \\ of Neonatology, Hangzhou Maternity and Child Health Care Hospital, Hangzhou, China \\ Contributions: (I) Conception and design: Z Zhang; (II) Administrative support: Z Zhang; (III) Provision of study materials or patients: L Ye, Z Zhang; \\ (IV) Collection and assembly of data: J Li, H Xia, L Ye, X Li; (V) Data analysis and interpretation: Z Zhang, J Li, H Xia; (VI) Manuscript writing: All \\ authors; (VII) Final approval of manuscript: All authors. \\ Correspondence to: Zhiqun Zhang. Department of Neonatology, Affiliated Hangzhou First People's Hospital, Zhejiang University School of Medicine, \\ No. 261 Huansha Road, Hangzhou 310002, China. Email: zhiqun.zhang@zju.edu.cn or zhiqun.zhang@163.com.
}

Background: Pulmonary hemorrhage is a potentially fatal event especially for preterm infants, which can lead to serious complications and even death. Many risk factors have been associated with the development of massive pulmonary hemorrhage. However, there is still no effective strategy to prevent massive pulmonary hemorrhage. The purpose of this study is to explore prediction model and survival strategies for massive pulmonary hemorrhage in premature infants.

Methods: In this retrospective study, we included all premature infants with birth weight $<1,500 \mathrm{~g}$ who were hospitalized in our neonatal intensive care unit (NICU) between January 012010 and December 31 2019.

Results: Of 599 preterm infants, 51 developed massive pulmonary hemorrhage. The logistic regression analysis showed that patent ductus arteriosus [odds ratio $(\mathrm{OR})=11.4$, 95\% confidence interval (CI): 4.79 27.0, $\mathrm{P}<0.0001$ ], coagulopathy (OR =6.56, 95\% CI: 2.83-15.2, $\mathrm{P}<0.0001)$, and 10-minute Apgar Score (OR $=0.52,95 \%$ CI: $0.37-0.73, \mathrm{P}=0.0001)$ were risk factors for massive pulmonary hemorrhage. Whether or not surfactant is used, the positive predictive value of combined patent ductus arteriosus and coagulopathy for predicting massive pulmonary hemorrhage was $68.9 \%$ and $70.4 \%$, respectively. Of the 51 preterm infants with massive pulmonary hemorrhage, 25 died and 26 survived. The survivors group had higher positive endexpiratory pressure compared with the deceased group after the onset of massive pulmonary hemorrhage. After adjusting for potential risk factors, the multiple logistic regression analysis showed that higher positive end-expiratory pressure levels are closely related to survival.

Conclusions: Patent ductus arteriosus combined with coagulopathy has a high predictive value for massive pulmonary hemorrhage. Higher positive end-expiratory pressure levels may reduce mortality in massive pulmonary hemorrhage.

Keywords: Pulmonary hemorrhage; ductus arteriosus; positive end-expiratory pressure; preterm infants; predictive model

Submitted Feb 11, 2021. Accepted for publication Apr 05, 2021.

doi: $10.21037 / \mathrm{tp}-21-64$

View this article at: http://dx.doi.org/10.21037/tp-21-64 


\section{Introduction}

Massive pulmonary haemorrhage $(\mathrm{MPH})$ is a serious fatal event especially for preterm infants, and is one of the main causes of premature death in early postnatal period (1). The earlier the gestational age (GA) and the lighter the birth weight $(\mathrm{BW})$ of premature infants is, the higher the incidence of PH. A large multicentre retrospective study showed that the incidence of $\mathrm{PH}$ ranged from $2.0 \%$ to $8.7 \%$ in preterm infants of GA 24 to 32 weeks (1). Similarly, the incidence of $\mathrm{PH}$ in preterm infants with $\mathrm{BW}$ less than $1,500 \mathrm{~g}$ ranged from $3.2 \%$ to $11 \%$ in different single-centre studies (2-4). In addition, MPH is associated with serious complications and mortality, and the mortality rate is high, ranging from $50 \%$ to $82 \%(1-3)$, and the survivors have an increased risk of chronic lung disease and poor long-term outcome $(5,6)$.

The proactive prevention of $\mathrm{MPH}$ and the fast and effective to prevent the progress of $\mathrm{PH}$ is important. Some studies have investigated the risk factors of $\mathrm{PH}$ in preterm infants (2-4). However, there is lack of research on early risk factors for a predictive model and strategies to improve the survival of preterm infants with MPH. Therefore, understanding high-risk factors and establishing predictive models for early intervention are the key to preventing $\mathrm{PH}$. In addition, exploring fast and effective measures to avoid death caused by $\mathrm{PH}$ is a concern for clinicians. The objective of this study was to explore prediction model based on the risk factors of MPH in preterm infants and the strategies to improve the survival of MPH.

We present the study in accordance with the STROBE reporting checklist (available at http://dx.doi.org/10.21037/ tp-21-64).

\section{Methods}

The study was conducted in accordance with the Declaration of Helsinki (as revised in 2013). This study was reviewed and approved by the ethics committee at Hangzhou First People's Hospital (No. 2020(102)-01). Patients were not required to give informed consent to the study because the analysis used anonymous clinical data that were obtained after each patient agreed to treatment by written consent.

\section{Study design}

We conducted a 10 -year retrospective study in the neonatal intensive care unit (NICU) of Hangzhou First People's Hospital between January 012010 and December 312019. The study population comprised preterm infants with a $\mathrm{BW}<1,500 \mathrm{~g}$ who were hospitalized to the NICU. Infants with major congenital malformations, those who abandoned treatment or died before 24 hours of life, or those for whom bedside echocardiographic or coagulation outcome data missing were excluded. We also created a matched sample of preterm infants with MPH and matched these infants to the control group with a ratio of $1: 2$ to identify potential risk factors, and we matched according to GA, BW and gender. All methods were carried out in accordance with Hangzhou First People's Hospital guidelines and regulations.

In accordance with the European Consensus Guidelines for the Management of Respiratory Distress Syndrome (RDS) (7-9), infants were intubated or given surfactant and other supportive measures included nutritional and antibiotic therapy. MPH is defined from the endotracheal catheter emerged large number of bloody liquids, acute clinical deterioration followed, and new ground glass or even white lung signs in the entire lung fields of X-ray (3). All preterm infants with MPH were given conventional mechanical ventilation (CMV).

Follow the routine of our NICU, coagulation screens are carried out on all very low birth weight (VLBW) and extremely low birth weight infants on the $1^{\text {th }}$ and $3^{\text {th }}$ day of life or there was a clinical suspicion of coagulation dysfunction or clinical deterioration. At least 1 coagulation screen was performed before PH occurred. Before the heparinized liquid infusion, blood samples were obtained by venipuncture, placed in a $2.5 \mathrm{~mL}$ standard citrate blood sample tube, and measured with a standardized blood to citrate ratio. The samples are processed according to predesignated laboratory techniques. At the same time, in accordance with standard procedures, a complete blood count was performed at least once within 3 days after birth. Once the $\mathrm{PH}$ or suspicious $\mathrm{PH}$ is recognized, a complete blood count is performed again. In our NICU, it was recommended to use fresh frozen plasma (FFP) if coagulation disorders (was defined according to clinical manifestation and laboratory results including skin ecchymosis or hemorrhagic spot, thrombocytopenia $\left(<100 \times 10^{9} / \mathrm{L}\right)$ with one of the following: prolonged PT (>21 s) and APTT (> 2 times normal control), reduced fibrinogen $(<100 \mathrm{mg} / \mathrm{dL})(10)$, but FFP supplementation was determined by the judgment of the attending physician. FFP $(15-20 \mathrm{~mL} / \mathrm{kg})$ transfusion was over approximately $6 \mathrm{~h}$. Furosemide $(0.5 \mathrm{mg} / \mathrm{kg})$ was given after the transfusion. 
Bedside echocardiographic examination for patent ductus arteriosus (PDA) included assessment the shunt direction of the ductal level by color Doppler and measurement the maximum inner diameter of the ductal in B-mode on the $1^{\text {th }}$ and $3^{\text {th }}$ day of life or there was a clinical suspicion of the condition or respiratory support needs to be upgraded. At least 1 bedside echocardiographic was performed before $\mathrm{PH}$ occurred. According to the following conditions: (I) presence of $\geq 2-3$ clinical or radiological signs, (II) PDA $(\mathrm{mm})$ to weight $(\mathrm{kg})$ ratio $\geq 1.5-2(11)$, it was recommended to use ibuprofen in the treatment of hemodynamically significant PDA with left-to-right shunt, but ibuprofen administration was determined by the judgment of the treating physician.

\section{Data collection}

Clinical data and outcome parameters were collected by two independent investigators ( $\mathrm{XL}$ and $\mathrm{LY}$ ) using standardized forms. Any differences and disagreements in the clinical data were discussed and resolved by consensus with another member of the research team (JL or ZZ). All authors had access to identifying information during or after data collection. Data were collected from electronic medical records system included BW, GA, gender, intrauterine growth restriction, type of delivery, and Apgar scores (at 5-, and 10-min). Prenatal factors including glucocorticoid administration, premature rupture of membranes, pregnancyinduced hypertension or preeclampsia, and diabetes were collected. Neonatal factors such as hypothermia $\left(<35^{\circ} \mathrm{C}\right)$, initial $\mathrm{pH}$ (within 1 hour after birth), early-onset sepsis (documented as clinical sepsis or positive blood culture within 7 days after birth), PDA, coagulation disorders, neonatal respiratory distress syndrome (RDS), use of surfactants, the ventilator parameters when $\mathrm{PH}$ occurs.

As prognostic variables, BPD was defined as oxygen dependence for more than 28 days and was graded according to the degree of oxygen dependence at 36 weeks' PMA: mild BPD (no oxygen requirement), moderate BPD $\left(\mathrm{FiO}_{2}<30 \%\right)$, and severe $\mathrm{BPD}\left(\mathrm{FiO}_{2} \geq 30 \%\right.$ and/or positive pressure support) (12), intraventricular hemorrhage (IVH) is classified according to the Papile standard (13), and outcome such as discharge or death were assessed.

\section{Statistical analyses}

Baseline differences between MPH group and no MPH group or matched group were compared with a $t$-test for quantitative data and a chi square test for categorical variables. It was a potential risk factor when $\mathrm{P}<0.1$ from the univariate analysis (MPH group vs. no MPH group or matched group), and the potential risk factors were subjected to multivariate logistic regression analysis to derive the adjusted odds ratio (OR) and $95 \%$ confidence interval (CI) for MPH and survival of MPH. Statistical significance was set at $\mathrm{P}<0.05$. All statistical analyses were performed using SAS 9.3 software (SAS Institute, Cary, NC, USA).

\section{Results}

A total of 647 premature infants with BW less than 1,500 grams were admitted to hospital between January 2010 and December 2019. We excluded 48 infants due to either transfer to another hospital or refusal of treatment within 24 hours after birth. Of the remaining 599 patients, 51 developed MPH, and the prevalence of among those whose $\mathrm{BW}$ was $<1,500 \mathrm{~g}$ was $6.1 \%$ and $22.9 \%$ among those with $\mathrm{BW}<1,000 \mathrm{~g}$. Thirty-six preterm infants with MPH occurred within 72 hours after birth. The clinical characteristics and outcomes are presented in Table 1. Compared with no MPH, preterm infants with MPH had significantly lower BW, smaller GA, and lower Median Apgar scores at 5- and 10-min. Differences in gender, initial $\mathrm{pH}$, use of surfactant, caffeine for apnea, incidence of early-onset septicemia, coagulation disorders, and PDA were also significant between the two groups. The group with MPH had a significantly higher IVH (grades 3 or 4), moderate or severe BPD, and mortality rate than the noMPH group. There were no differences in intrauterine growth restriction, prenatal steroid use, vaginal delivery, incidence of maternal PIH, diabetes, premature rupture of membranes, and hypothermia between the two groups. An evaluation of outcomes in the matched sample also finds that infants with MPH had significantly lower Apgar scores and higher rates of RDS, early-onset septicemia, coagulation disorders, PDA, IVH, moderate or severe BPD, and death compared with controls (Table 1).

Factors related to the incidence of $\mathrm{MPH}$ in premature infants in univariate analysis included BW, GA, gender, hypothermia, initial $\mathrm{pH}$, Apgar scores at 5 and $10 \mathrm{~min}$, surfactant use, early-onset septicemia, coagulation disorders, and PDA. After adjustment for confounding factors, using multivariate logistic regression, in which only Apgar scores at $10 \mathrm{~min}(\mathrm{OR}=0.52,95 \% \mathrm{CI}$ : $0.37-0.73$, $\mathrm{P}=0.0001)$, coagulation disorders $(\mathrm{OR}=6.56,95 \% \mathrm{CI}$ : 
Table 1 Comparison of demographic and clinical characteristics between patients with and without MPH

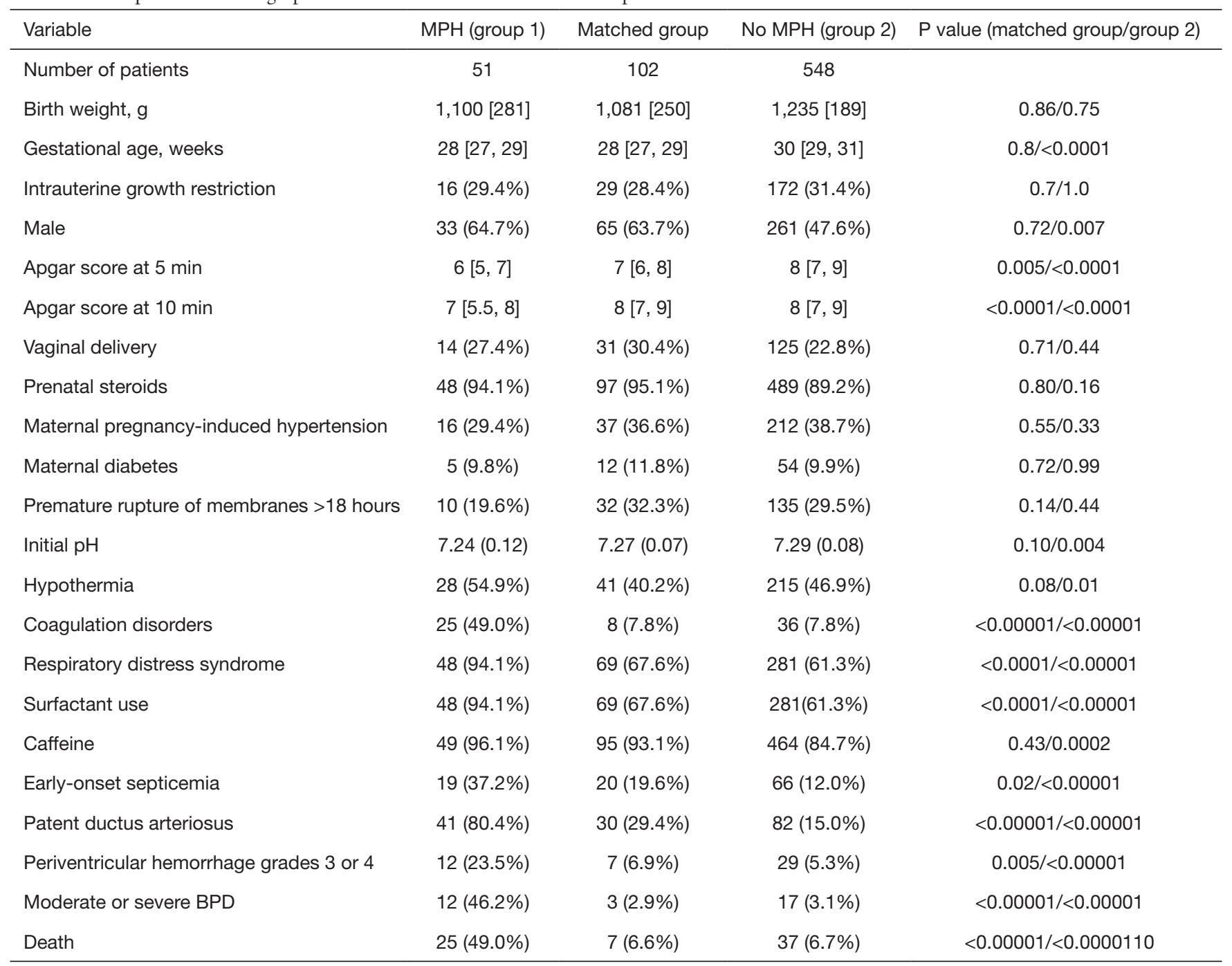

$\mathrm{MPH}$, massive pulmonary haemorrhage.

2.83-15.2, $\mathrm{P}<0.0001)$ and $\mathrm{PDA}(\mathrm{OR}=11.4,95 \% \mathrm{CI}: 4.79$ 27.0, $\mathrm{P}<0.0001$ ) maintained the association (Figure 1). The predictive value of single factor and a combination of factors is shown in Figure 2. The highest positive predictive value (PPV) of combination PDA, surfactant use and coagulation disorders was $70.4 \%$. The PPV of combination PDA and coagulation disorders was $67.7 \%$. The negative predictive value of all single factors and a combination of them was over $93.5 \%$.

Of the 51 preterm infants with MPH, 26 survived and 25 died. There were no differences in GA, BW, Apgar score at 5 mins and 10 mins, Initial $\mathrm{pH}$, use of surfactant after $\mathrm{PH}$, and incidence of RDS and early-onset septicemia between the deceased group and survived group (Table 2). Among preterm infants with $\mathrm{MPH}$, the survived group received more ibuprofen treatment $(70.0 \%$ vs. $4.0 \%$, $\mathrm{P}=0.009)$ and $\mathrm{FFP}$ support $(84.6 \%$ vs. $44.0 \%, \mathrm{P}=0.007)$ than the deceased group (Table 2). In addition, the survived group had higher positive end-expiratory pressure (PEEP) respiratory support compared with the deceased group after the onset of MPH $\{7[6,8.75]$ vs. $6[5,6], \mathrm{P}<0.0001\}$ (Table 2). All preterm infants with MPH were given epinephrine by airway administration. After adjustments for basic clinical characteristics, using multivariate logistic regression, only PEEP maintained the association $(\mathrm{OR}=4.35,95 \% \mathrm{CI}$ : $1.40-13.52, \mathrm{P}=0.01$ ) (Table 3). 


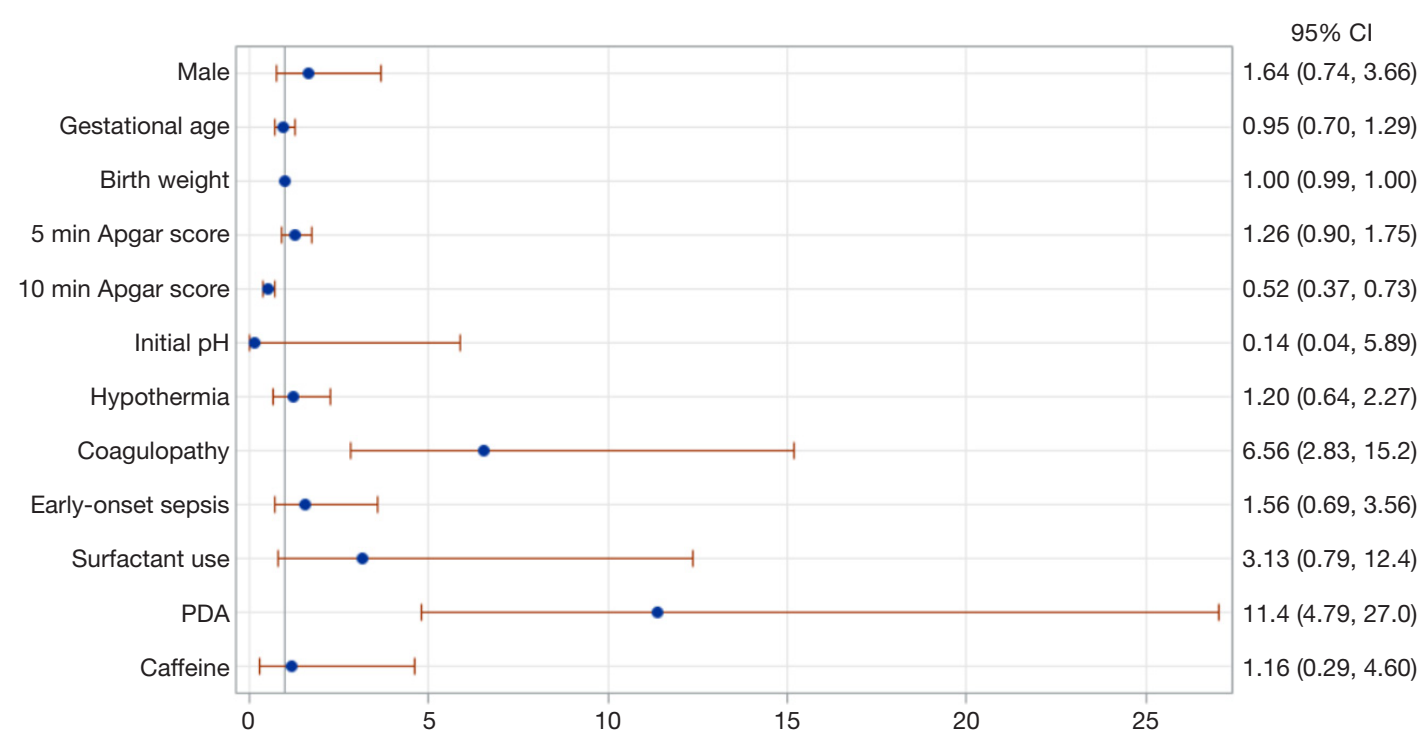

Figure 1 Multivariate analysis of MPH risk factors by logistic regression. PDA, patent ductus arteriosus; MPH, massive pulmonary haemorrhage.

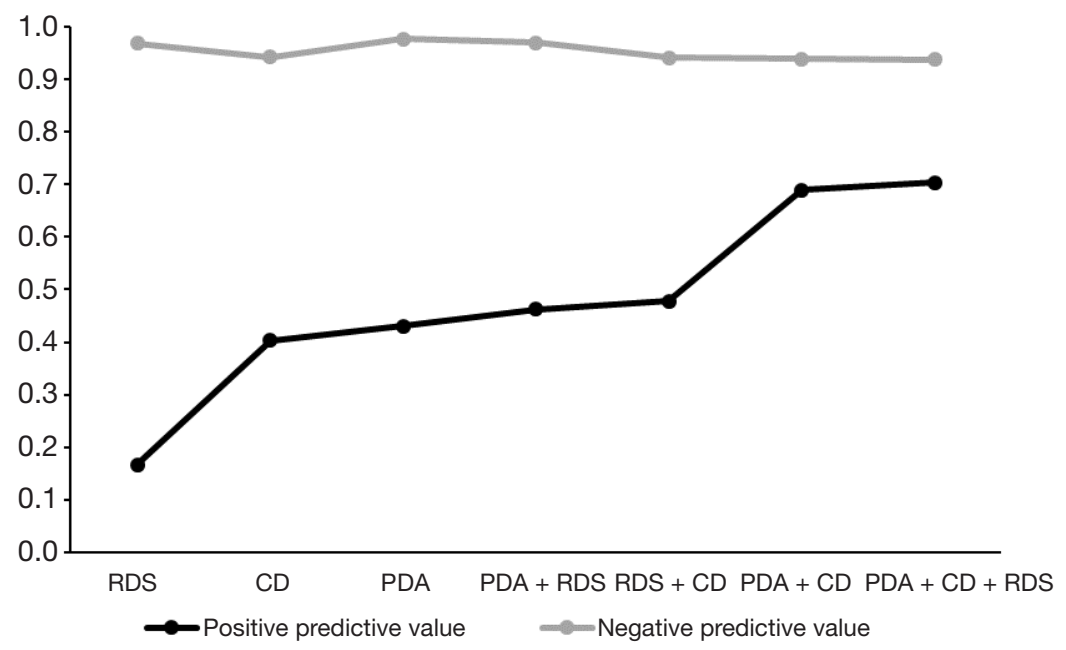

Figure 2 Predictive value of single factor and a combination of factors. RDS, respiratory distress syndrome; CD, coagulation disorders; PDA, patent ductus arteriosus.

\section{Discussion}

The present study identified that PDA, coagulation disorders, and low Apgar scores at $10 \mathrm{~min}$ increased the risk of $\mathrm{MPH}$ in premature infants. The association between factors and MPH stayed consistent even after adjustment for confounding factors including GA, BW, gender, initial pH, Apgar scores at 5 and $10 \mathrm{~min}$, hypothermia, surfactant use, early-onset septicemia in a logistic regression analysis $(\mathrm{P}<0.0001$,
$\mathrm{P}<0.0001$, and $\mathrm{P}=0.0001)$. The PPV of combined PDA and coagulopathy for predicting MPH was more than $2 / 3$. When $\mathrm{PH}$ occurs, regression analysis showed higher PEEP levels can reduce mortality in premature infants of $\mathrm{MPH}$.

It can be inferred that asphyxiating infants, especially those of small GA or low BW, are more vulnerable to harmful events (3). Our research implied that low Apgar scores at $10 \mathrm{~min}$ is an independent risk factor for MPH. It means that newborns may be in more depressed states and 
Table 2 Basic clinical characteristics and management of the MPH population

\begin{tabular}{|c|c|c|c|}
\hline Variable & Deceased & Survived & $P$ value \\
\hline Number of patients & 25 & 26 & \\
\hline Male & 17 (68.0\%) & $16(61.5 \%)$ & 0.63 \\
\hline Birth weight, $g$ & $1,089[275]$ & $1,096.5[261]$ & 0.86 \\
\hline Gestational age, weeks & $28[27.5,29]$ & $28[27,29]$ & 0.92 \\
\hline Apgar score at 5 min & $6[5,7]$ & $6[6,7]$ & 0.81 \\
\hline Apgar score at $10 \mathrm{~min}$ & $6[5,7]$ & $7[6,7.75]$ & 0.18 \\
\hline Initial pH & $7.23(0.13)$ & $7.24(0.11)$ & 0.76 \\
\hline Hypothermia & $13(52.0 \%)$ & $15(57.7 \%)$ & 0.68 \\
\hline $\begin{array}{l}\text { Respiratory distress } \\
\text { syndrome }\end{array}$ & 23 (92.0\%) & $26(100 \%)$ & 0.23 \\
\hline Caffeine & $24(96.0 \%)$ & $25(96.2 \%)$ & 0.98 \\
\hline Early-onset septicemia & $10(40.0 \%)$ & $9(34.6 \%)$ & 0.69 \\
\hline PDA & 23 (92.0\%) & 20 (76.9\%) & 0.14 \\
\hline Ibuprofen for PDA & $1(4.0 \%)$ & $14(70.0 \%)$ & 0.009 \\
\hline Plasma support therapy & $11(44.0 \%)$ & $22(84.6 \%)$ & 0.007 \\
\hline PEEP & $6(5,6)$ & $7(6,8.75)$ & $<0.0001$ \\
\hline $\begin{array}{l}\text { Use of surfactant after } \\
\text { pulmonary hemorrhage }\end{array}$ & $16(64.0 \%)$ & $16(61.5 \%)$ & 0.86 \\
\hline $\begin{array}{l}\text { Epinephrine use } \\
\text { (intratracheal instillation) }\end{array}$ & $25(100 \%)$ & $26(100 \%)$ & 1 \\
\hline
\end{tabular}

PDA, patent ductus arteriosus; PEEP, positive end-expiratory pressure.

Table 3 Summary table of logistic regression with survived in MPH as the dependent variable and management as independent variables

\begin{tabular}{lccc}
\hline Variable & Adjusted OR & $95 \% \mathrm{Cl}$ & $\mathrm{P}$ value \\
\hline Ibuprofen for PDA & 4.01 & $0.64-25.37$ & 0.14 \\
Plasma support therapy & 2.54 & $0.47-13.67$ & 0.28 \\
PEEP & 4.35 & $1.40-13.52$ & 0.01 \\
\hline
\end{tabular}

$\mathrm{MPH}$, massive pulmonary haemorrhage; PDA, patent ductus arteriosus; OR, odds ratio; $\mathrm{Cl}$, confidence interval; PEEP, positive end-expiratory pressure.

require stronger resuscitation or even ventilator support, which were likely to cause excessive expansion of the alveoli, causing pressure damage to the alveolar capillaries, so as to promote the occurrence of $\mathrm{PH}$. These are, in part, consistent with findings of Yum et al. (3) in that low
Apgar scores at $5 \mathrm{~min}$ increased the incidence of $\mathrm{MPH}$ and affected the survival of infants with MPH. However, Apgar score at 5 mins and 10 mins are similar between the deceased group and survived group in preterm infants with MPH in our study. Due to consistent clinical baseline data, risk factors affecting mortality in MPH may be enough objective in our study.

The use of surfactant also showed an association in a multivariate logistic regression model. It has been reported that the prevention or treatment of RDS by surfactant increases the risk of $\mathrm{PH}(14,15)$. After surfactant treatment, lung compliance improved, and left-to-right shunts of the arterial duct increased, which may contribute to $\mathrm{PH}$ (16). Surfactant treatment has also been demonstrated to impair coagulation in vitro (17). As for coagulopathy, few studies have specifically analyzed the correlation between coagulopathy and the risk and outcome of MPH in preterm infants (3). In our study, the MPH group had more coagulopathy. The survival group had more patients received plasma treatment, but multivariate logistic regression showed that plasma treatment did not increase survival. In the meantime, recent studies have also presented similar strategies, such as the using haemocoagulase or recombinant factor VII, as potential therapy for $\mathrm{PH}(18,19)$. By contrast, Usemann et al. (20) found that infusion of FFP $(10-20 \mathrm{~mL} / \mathrm{kg})$ within 4 hours increased the risk of pulmonary hemorrhage. They speculate the transfusion plasma from adult donors may cause adverse effects on neonatal platelet function, and it could lead to the destruction of the pulmonary vascular endothelial barrier and subsequent bleeding (20). There is still controversy in the treatment of plasma support, and more clinical trials and experimental research in animal models are needed to clarify the role and potential mechanisms of FFP for lung diseases in prematurity.

Studies have confirmed that PDA is closely related to PH $(1,4,21,22)$. PDA causes shunting from left-to-right, which in turn leads to high flow and high-pressure damage to the vascular bed $(14,21)$. Kluckow et al. (22) found that significant ductal shunting and high estimated pulmonary blood flow were related to $\mathrm{PH}$ in premature infants. Subsequently, their RCT showed that infants with large PDA and early indomethacin treatment had a significantly fewer early $\mathrm{pH}$ compared with infants who were not treated with indomethacin (23). Similar to the above findings, in our study, PDA increased the risk of MPH in preterm infants. These confirm the importance of closure of the PDA in preterm infants with high risk of MPH. 
To the best of our knowledge, our study is the first to explore the use of risk factors to predict $\mathrm{MPH}$. The PPV of the combination of PDA and coagulation dysfunction is $68.9 \%$, combining PDA, coagulation dysfunction, and the use of pulmonary surfactant gives a PPV of $70.4 \%$. That is, when a premature infant has both PDA and coagulation dysfunction, or when PDA, coagulation dysfunction, and the use of pulmonary surfactant are all present, the probability of $\mathrm{MPH}$ is close to $70 \%$. Therefore, when premature infants have the above risk factors, we should actively close the PDA and improve coagulation function. In the future, more research is needed to confirm our results, including a prospective multicentre cohort study.

For airspace events, PEEP can increase mean airway pressure (24), edema flooded alveoli or recruit atelectatic $(25,26)$ and prevent cyclic alveolar collapse and reexpansion (27). For preterm infants with $\mathrm{PH}$, it needs to be appropriate and high PEEP to stop bleeding. A ventilation strategy of high PEEP is used to redistribute lung water, back into the interstitial space, improving oxygenation and ventilation-perfusion balance (28). An animal study confirmed that the application of a moderate level of PEEP has protective effects, which was shown to reduce the formation of edema and PH (29). In our study, the survived group had higher PEEP compared with the deceased group after the onset of MPH. The association also persisted even after adjustment for confounding variables. Among the survivors in MPH, 11 preterm infants of PEEP ware over $6 \mathrm{cmH}_{2} \mathrm{O}$, and the highest PEEP reached $20 \mathrm{cmH}_{2} \mathrm{O}$. These data indicate that higher PEEP could be used as an alternative ventilator therapy for preterm infants with severe $\mathrm{PH}$. There are also studies that high frequency oscillatory ventilation (HFOV) could be used as an alternative ventilator therapy in cases where CMV fails to support VLBW infants with severe PH (30-32). Survival rates in these studies ranged from $59 \%$ to $100 \%$ by HFOV for preventing PH in VLBW infants (30-32). In these studies, the number of $\mathrm{PH}$ cases was 17 to 18 , the sample size was small, and the definition of $\mathrm{PH}$ was not completely consistent (30-32). When MPH occurs, the initial pressure setting is very critical, which can achieve hemostasis and improve oxygenation. According to the principle of $\mathrm{HFOV}$, the initial mean airway pressure (MAP) of HFOV is often $2-3 \mathrm{cmH}_{2} \mathrm{O}$ higher than that of CMV (33), and this higher MAP may play an important role. An evidence-based recommendation on HFOV published in the early years also showed the available randomized controlled trials comparing HFOV with
CMV have not demonstrated any clear benefit of HFOV for neonates who have respiratory insufficiency (33). However, for preterm infants with MPH, further randomized controlled trials are still needed to compare the effectiveness and safety of the two ventilation modes.

This study has certain limitations, as it is a retrospective study, and the time span is relatively long, there are inconsistencies in treatment standards. The loss of 48 premature infants to follow-up might have affected the final results to some extent. Although we adjusted the known confounding factors of MPH, we could not completely exclude other factors that may influence MPH. In addition, because our study focused on exploring prediction model and survival strategies for $\mathrm{MPH}$ in premature infants, we did not observe long-term neurodevelopmental outcome in survived infants. Future follow-up studies will be conducted.

\section{Conclusions}

Our study indicate that MPH is associated with PDA, coagulation disorders, and low Apgar scores at $10 \mathrm{~min}$, resulting in higher mortality and BPD. PDA combined with coagulation disorders has a high predictive value of MPH. When PH occurs, sufficient PEEP levels may reduce mortality in premature infants of $\mathrm{MPH}$. Our results still need to be confirmed by a large-scale prospective and rigorously designed study.

\section{Acknowledgments}

Funding: This work was supported by Natural Science Foundation of Zhejiang Province (grant number LY15H040002, LY20H040008). The funding source play no role in study design, data collection, data analysis, data interpretation, writing of the report, or in the decision to submit the report for publication.

\section{Footnote}

Reporting Checklist: The authors have completed the STROBE reporting checklist. Available at http://dx.doi. org/10.21037/tp-21-64

Data Sharing Statement: Available at http://dx.doi. org/10.21037/tp-21-64

Conflicts of Interest: All authors have completed the ICMJE uniform disclosure form (available at http://dx.doi. 
org/10.21037/tp-21-64). The other authors have no conflicts of interest to declare.

Ethical Statement: The authors are accountable for all aspects of the work in ensuring that questions related to the accuracy or integrity of any part of the work are appropriately investigated and resolved. The study was conducted in accordance with the Declaration of Helsinki (as revised in 2013). This study was reviewed and approved by the ethics committee at Hangzhou First People's Hospital (No. 2020(102)-01). Patients were not required to give informed consent to the study because the analysis used anonymous clinical data that were obtained after each patient agreed to treatment by written consent.

Open Access Statement: This is an Open Access article distributed in accordance with the Creative Commons Attribution-NonCommercial-NoDerivs 4.0 International License (CC BY-NC-ND 4.0), which permits the noncommercial replication and distribution of the article with the strict proviso that no changes or edits are made and the original work is properly cited (including links to both the formal publication through the relevant DOI and the license). See: https://creativecommons.org/licenses/by-nc-nd/4.0/.

\section{References}

1. Ahmad KA, Bennett MM, Ahmad SF, et al. Morbidity and mortality with early pulmonary haemorrhage in preterm neonates. Arch Dis Child Fetal Neonatal Ed 2019;104:F63-8.

2. Scholl JE, Yanowitz TD. Pulmonary hemorrhage in very low birth weight infants: a case-control analysis. J Pediatr 2015;166:1083-4.

3. Yum SK, Moon CJ, Youn YA, et al. Risk factor profile of massive pulmonary haemorrhage in neonates: the impact on survival studied in a tertiary care centre. J Matern Fetal Neonatal Med 2016;29:338-43.

4. Lin TW, Su BH, Lin HC, et al. Risk factors of pulmonary hemorrhage in very-low-birth-weight infants: a two-year retrospective study. Acta Paediatr Taiwan 2000;41:255-8.

5. Pandit PB, O'Brien K, Asztalos E, et al. Outcome following pulmonary haemorrhage in very low birthweight neonates treated with surfactant. Arch Dis Child Fetal Neonatal Ed 1999;81:F40-4.

6. Alfaleh K, Smyth JA, Roberts RS, et al. Prevention and 18-month outcomes of serious pulmonary hemorrhage in extremely low birth weight infants: results from the trial of indomethacin prophylaxis in preterms. Nature 2019;568:499-504.

7. Sweet DG, Carnielli V, Greisen G,et al; European Association of Perinatal Medicine. European consensus guidelines on the management of neonatal respiratory distress syndrome in preterm infants - 2010 update. Neonatology 2010;97:402-17.

8. Sweet DG, Carnielli V, Greisen G, et al; European Association of Perinatal Medicine. European consensus guidelines on the management of neonatal respiratory distress syndrome in preterm infants--2013 update. Neonatology 2013;103:353-68.

9. Sweet DG, Carnielli V, Greisen G, et al. European Consensus Guidelines on the Management of Respiratory Distress Syndrome - 2016 Update. Neonatology 2017;111:107-25.

10. Gibson BE, Todd A, Roberts I, et al; British Commitee for Standards in Haematology Transfusion Task Force: Writing group. British Committee for Standards in Haematology Transfusion Task Force: Writing Group. Transfusion guidelines for neonates and older children. $\mathrm{Br}$ J Haematol 2004; 124:433-53.

11. Jain A, Shah PS. Diagnosis, Evaluation, and Management of Patent Ductus Arteriosus in Preterm Neonates. JAMA Pediatr 2015;169:863-72.

12. Jobe AH, Bancalari E. Bronchopulmonary dysplasia. Am J Respir Crit Care Med 2001;163:1723-9.

13. Papile LA, Burstein J, Burstein R, et al. Incidence and evolution of subependymal and intraventricular hemorrhage: A study of infants with birth weights less than 1,500 gm. J Pediatr 1978;92:529-34.

14. Raju TN, Langenberg P. Pulmonary hemorrhage and exogenous surfactant therapy: a meta-analysis. J Pediatr 1993;123:603-10.

15. Pappin A, Shenker N, Hack M, et al. Extensive intraalveolar pulmonary hemorrhage in infants dying after surfactant therapy. J Pediatr 1994;124:621-6.

16. Su BH, Lin HY, Huang FK, et al. Circulatory Management Focusing on Preventing Intraventricular Hemorrhage and Pulmonary Hemorrhage in Preterm Infants. Pediatr Neonatol 2016;57:453-62.

17. Strauss T, Rozenzweig N, Rosenberg N, et al. Surfactant impairs coagulation in-vitro: a risk factor for pulmonary hemorrhage? Thromb Res 2013;132:599-603.

18. Shi Y, Zhao J, Tang S, et al. Effect of hemocoagulase for prevention of pulmonary hemorrhage in critical newborns on mechanical ventilation: a randomized controlled trial. Indian Pediatr 2008;45:199-202. 
19. Cosar H, Isik H, Cakır SC, et al. Recombinant Activated Factor VIIa (rFVIIa) Treatment in Very-Low-BirthWeight (VLBW) Premature Infants with Acute Pulmonary Hemorrhage: A Single-Center, Retrospective Study. Paediatr Drugs 2017;19:53-8.

20. Usemann J, Garten L, Bührer C, et al. Fresh frozen plasma transfusion - a risk factor for pulmonary hemorrhage in extremely low birth weight infants? J Perinat Med 2017;45:627-33.

21. Garland J, Buck R, Weinberg M. Pulmonary hemorrhage risk in infants with a clinically diagnosed patent ductus arteriosus: A retrospective cohort study. Pediatrics 1994;94:719-23.

22. Kluckow M, Evans N. Ductal shunting, high pulmonary bloodflow, and pulmonary hemorrhage. J Pediatr 2000;137:68-72.

23. Kluckow M, Jeffery M, Gill A, et al. A randomized placebo-controlled trial of early treatment of patent ductus arteriosus. Am J Gastroenterol 2010;105:2610-6.

24. Dreyfuss D, Soler P, Basset G, et al. High inflation pressure pulmonary edema. Respective effects of high airway pressure, high tidal volume, and positive endexpiratory pressure. Am Rev Respir Dis 1988;137:1159-64.

25. Webb HH, Tierney DF. Experimental pulmonary edema due to intermittent positive pressure ventilation with high inflation pressures. Protection by positive end-expiratory pressure. Am Rev Respir Dis 1974;110:556-65.

Cite this article as: Li J, Xia H, Ye L, Li X, Zhang Z. Exploring prediction model and survival strategies for pulmonary hemorrhage in premature infants: a single-center, retrospective study. Transl Pediatr 2021;10(5):1324-1332. doi: $10.21037 /$ tp-21-64
26. Valenza F, Guglielmi M, Irace M, et al. Positive endexpiratory pressure delays the progression of lung injury during ventilator strategies involving high airway pressure and lung overdistention. Crit Care Med 2003;31:1993-8.

27. Simonson DA, Adams AB, Wright LA, et al. Effects of ventilatory pattern on experimental lung injury caused by high airway pressure. Crit Care Med 2004;32:781-6.

28. Narasimhan R, Papworth S. Pulmonary haemorrhage in the neonate. Paediatrics \& Child Health 2009;19:171-3.

29. Piacentini E, López-Aguilar J, García-Martín C, et al. Effects of vascular flow and PEEP in a multiple hit model of lung injury in isolated perfused rabbit lungs. J Trauma 2008;65:147-53.

30. AlKharfy TM. High-frequency ventilation in the management of very-low-birth-weight infants with pulmonary hemorrhage. Am J Perinatol 2004;21:19-26.

31. Ko SY, Chang YS, Park WS. Massive pulmonary hemorrhage in newborn infants successfully treated with high frequency oscillatory ventilation. J Korean Med Sci 1998;13:495.

32. Yen TA, Wang CC, Hsieh WS, et al. Short-term outcome of pulmonary hemorrhage in very-low-birth-weight preterm infants. Pediatr Neonatol 2013;54:330-4.

33. Lampland AL, Mammel MC. The role of high-frequency ventilation in neonates: evidence-based recommendations. Clin Perinatol 2007;34:129-44. 